\title{
Nanoporous molecular crystals
}

\author{
Neil B. McKeown* \\ Received 11th June 2010, Accepted 5th August 2010
DOI: 10.1039/c0jm01867h
}

Nanoporous Molecular Crystals (NMCs) are nanoporous materials composed of discrete molecules between which there are only non-covalent interactions - i.e. they do not possess an extended framework composed of covalent or coordination bonds. They are formed from removing guest molecules from inclusion compounds (ICs) a process that for most ICs usually results in the collapse of the open structure of the crystals but in the case of NMCs the packing of the host molecules is retained and nanoporosity obtained. In recent years a number of NMCs have been confirmed by the technique of gas adsorption and these materials are surveyed in this feature article. In addition, the reasons for stability of these crystals are discussed. It is the author's belief that many more ICs, the structures of which are readily obtainable from the Cambridge Structural Database (CSD), may act as precursors to NMCs.

\section{Introduction}

It is now accepted that molecular crystals possess desirable electronic, optical and electro-optical properties and can be exploited as materials for useful applications. ${ }^{1}$ This review sets out to convince its readers that some molecular crystals may also be considered as nanoporous materials with properties that are very different from those which are routinely available at present. Nanoporous materials are solids containing interconnected pores of molecular-sized dimensions and are widely used for heterogeneous catalysis, adsorption, separation, gas storage and a number of emerging technologies. ${ }^{2-5}$ Conventional nanoporous materials consist of crystalline inorganic frameworks (e.g., zeolites and related structures) or amorphous structures (e.g., silica and activated carbon). ${ }^{6}$ However, the past decade has seen

School of Chemistry, Cardiff University, Cardiff, CF10 3AT, UK. E-mail: mckeownnb@cardiff.ac.uk; Tel: +44 (0)2920875851

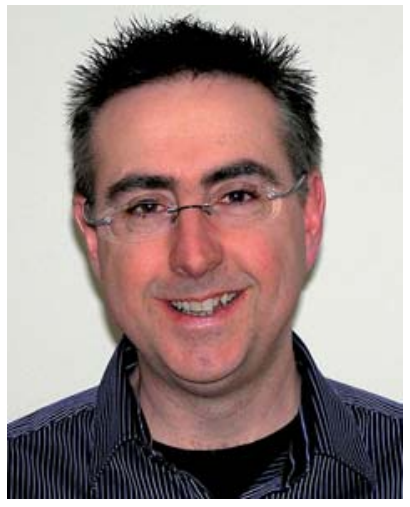

Neil B. McKeown
Neil B. McKeown is a Professor of Materials Chemistry at Cardiff University. He received his $P h D$ in organic chemistry from the University of East Anglia in 1987. After postdoctoral research at York University (Canada) and the University of Toronto, he obtained his first independent academic post at the University of Manchester in 1991 where he stayed until moving to Cardiff in 2004. His interests span many aspects of organic materials chemistry with particular recent emphasis on the synthesis of nanoporous molecular crystals and polymers of intrinsic microporosity. For the latter he was awarded the Beilby Medal by the RSC in 2008. major advances in the preparation of nanoporous materials using molecular components. ${ }^{7,8}$ For example, great interest has been generated by crystalline organic-inorganic hybrid materials, such as the Metal-Organic Frameworks (MOFs), also called Porous Coordination Polymers (PCPs). ${ }^{9-15}$

Nanoporous Molecular Crystals (NMCs) are composed of discrete molecules between which there are only non-covalent interactions-i.e. they do not possess an extended framework composed of covalent or coordination bonds. Such materials combine nanoporosity with the ability to be dissolved and then reassembled in appropriate solvents and as such may be valuable for the deployment of different methods of solvent-based fabrication, and hence, applications that are unsuitable for conventional nanoporous materials. ${ }^{16}$

In general, molecular solids pack space so as to maximise attractive interactions and, hence, minimise the amount of void space (empty space is wasted space). ${ }^{17,18}$ For all nanoporous materials prepared by a solvent-based synthesis, nanoporosity does not occur spontaneously during their formation but instead it is revealed only by the subsequent removal of included solvent molecules from inside the material. This evacuation of the nanopores creates an internal surface, which involves a high thermodynamic cost, so that all evacuated nanoporous materials are less stable (i.e. metastable) than a densely packed material of similar composition. The lack of a covalent framework means that most molecular crystals with included solvent cannot pay the thermodynamic cost associated with the removal of solvent and so their structures collapse. Indeed the breakthrough property of MOFs and PCPs, as compared to the many previously obtained open-framework coordination polymers, ${ }^{19-21}$ is that their structure is maintained during solvent evacuation to provide what is often called 'permanent' nanoporosity., ${ }^{9,22,23}$ Until recently, NMCs were at a similar stage of development to that of MOFs about 15 years ago in that a large number of solvent-containing "open" structures had been identified by single crystal X-ray diffraction (XRD), ${ }^{20}$ however, despite the pioneering work of Barrer et al. which predates the development of MOFs by many years, ${ }^{24-26}$ it was still generally accepted that the total removal of the solvent within inclusion compounds 
would destroy the crystal. This feature article will review the significant number of molecular crystals that have now been confirmed to possess permanent nanoporosity and will go on to suggest that these examples may only be the tip of an iceberg.

\section{The 'burden of proof' for nanoporous molecular crystals}

An analysis of the Cambridge Structural Database (CSD) ${ }^{27}$ suggests that at least $15 \%$ of molecules that form crystals do so with the incorporation of another molecule to give an inclusion compound (IC). ${ }^{28-30}$ In many cases, the included molecules, usually originating from the solvent of crystallisation, can be removed by heating, the application of a vacuum, or in some cases, even simply exposure to the atmosphere. As noted above, solvent removal most often results in destruction of the original crystalline order resulting in either a more dense crystal structure $^{31}$ (Fig. 1a) or an amorphous material (Fig. 1c). However, it has been recognised for many years that for many ICs the guest molecules can be replaced with another guest without loss of crystalline order (Fig. 1b) ${ }^{32-35}$ The close analogy of this behaviour to that of conventional nanoporous materials gave rise to the oxymoronic term 'organic zeolite', which strongly implies permanent nanoporosity such as that possessed by conventional nanoporous materials. Unfortunately, this term has been indiscriminately applied to a range of diverse materials. ${ }^{36-44}$ Therefore, we prefer the term nanoporous molecular crystal (or microporous molecular crystal) ${ }^{45}$ to describe a crystal composed of discrete molecules that demonstrate permanent porosity.

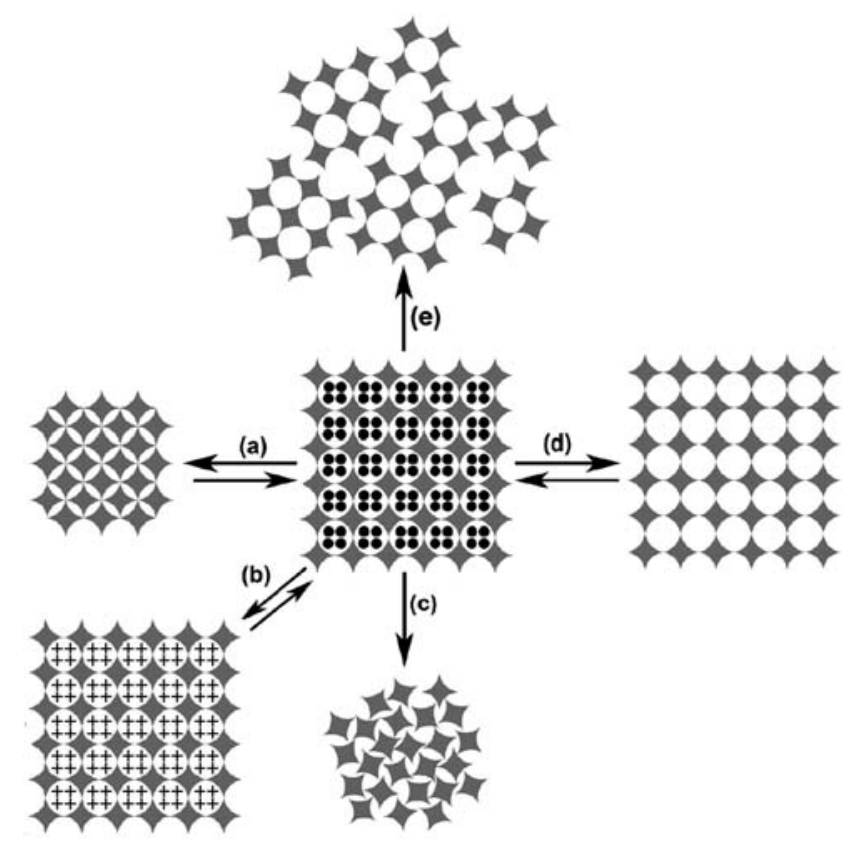

Fig. 1 Possible processes involving removal or exchange of included solvent within an IC: (a) transformation to a non-porous, denser crystal; (b) exchange of included solvent; (c) collapse of crystal structure to a nonporous amorphous solid; (d) formation of a NMC and (e) formation of an NMC accompanied by fragmentation of the crystal due to internal stress caused by a reduction in unit cell size.
In a clearly-argued article, Barbour suggested that investigators carry the "burden of proof" when they claim that a molecular crystal is nanoporous as there are numerous examples of 'virtual nanoporosity' in which the included solvent molecules are removed in silico to reveal voids. ${ }^{46}$ It can also be the case that highly disordered included solvent is not resolved by XRD and therefore the crystal structure can appear nanoporous, or that crystal structure is retained when only a small amount of solvent remains but not on complete evacuation. ${ }^{47,48}$ Therefore, Barbour suggested that the most conclusive evidence for permanent nanoporosity is reversible gas adsorption subsequent to the complete removal of included molecules. However, the 'proof' of nanoporosity provided by gas adsorption is perhaps more complex than it seems at first glance due to the dynamic nature of molecular crystals, a factor that is easily overlooked when examining a static representation of a single crystal XRD structure. It has been established that some crystals adsorb gas reversibly even though they cannot be described as nanoporous because channels of sufficient diameter to allow the unrestricted transit of the gas molecules do not interconnect the voids that they contain. An example of a gas-adsorbing but non-porous crystal is that of 4-tert-butylcalix[4]arene 1, which has been rigorously studied by both Atwood et al. ${ }^{49-54}$ and Ripmeester et al. ${ }^{55-58}$ Although no permanent open channels exist for facile transport of gas molecules (e.g. $\mathrm{CO}_{2}$ and $\mathrm{CH}_{4}$ ) to the voids provided by the bowl-shaped calixarene, the crystals of 1 must be permeable. It appears that the mechanism of transport through this non-porous crystal is directly analogous to that which allows gas transport through glassy polymers driven by a partial pressure difference. Glassy polymers possess excess free volume in the form of small voids, within which sorption of small molecules can occur. Small molecules may also 'dissolve' in and be transported through the dense regions of the polymer - a process that depends upon the local motion of the polymer chains. However, the movement of the polymer to accommodate the gas molecules is relatively slow compared to diffusion of the gas molecule within the voids. This mechanism of gas permeability is termed the solution-diffusion model $^{59}$ and was developed to explain the performance of polymeric gas separation membranes but could equally apply to the adsorption of gases within non-porous crystals. The adsorption of $\mathrm{CO}_{2}$ and $\mathrm{H}_{2} \mathrm{O}$ within non-porous crystals of the antibiotic Clarithromycin ${ }^{60}$ and gas uptake within other formally non-porous crystals, ${ }^{47,61-66}$ including a very recent example that demonstrates the catalytic hydrogenation of ethene within the non-porous molecular crystal of an indium complex, ${ }^{67}$ are likely to proceed via a similar dynamic mechanism of adsorption. It is notable that the adsorption of gases within these non-porous crystals is usually measured at ambient temperatures for which molecular motions of the host will be greater and thus the kinetics of adsorption will be faster, whereas conventional gas adsorption analysis of nanoporous materials is carried out at relatively low temperatures (e.g. $77 \mathrm{~K}$ ). Conversely, surface diffusion is likely to be the predominant mechanism for barrierfree gas permeability through a truly nanoporous crystal. In addition, the kinetics of adsorption for a nanoporous crystal will be enhanced by the attractive van der Waals interactions at the pore openings causing accelerated entrance velocity. ${ }^{68}$ Therefore, the nanoporosity of a molecular crystal cannot be defined by gas adsorption alone but rather by the demonstration of rapid 
barrier-free mechanisms of adsorption. For example, it is possible to establish permanent nanoporosity by the observation of $\mathrm{N}_{2}$ adsorption at $77 \mathrm{~K}$, typically at low relative pressures, and hence determine nanopore volume and even derive an apparent surface area by well-established methodologies such as BET (Brunauer, Emmett and Teller) analysis of the resulting isotherm. ${ }^{69}$ Another method of demonstrating nanoporosity via gas adsorption is hyperpolarised ${ }^{129} \mathrm{Xe}$ NMR, which can give valuable information on the binding sites within NMCs. ${ }^{70-77}$ However, the mechanism of adsorption may vary for different adsorbates, for example, $\mathrm{N}_{2}$ and $\mathrm{Xe}$ are relatively large probe molecules that are excluded from a number of porous zeolites and MOFs, ${ }^{78,79}$ therefore, smaller gas probes (e.g. $\mathrm{H}_{2}$ at $77 \mathrm{~K}$ or $\mathrm{CO}_{2}$ at $273 \mathrm{~K}$ ) may be more appropriate for the demonstration of rapid barrier-free adsorption within nanoporous crystals with very narrow access channels $(<3 \AA)$. ${ }^{107}$ Such molecular discrimination on the basis of size (molecular sieving) leads to important applications of nanoporous materials such as gas separation via pressure-swing adsorption and similar applications are envisaged for NMCs. ${ }^{108}$ Helium pycnometry, whereby the measured skeletal density of the unsolvated molecular crystal can be compared with that calculated from its crystal structure, is also of value for establishing nanoporosity within molecular crystals with very narrow micropores, as it is dependent upon the accessibility of the voids to the small He gas probe (kinetic diameter $=2.4 \AA$ A). ${ }^{71,73}$

As Barbour notes, ${ }^{46} \mathrm{NMCs}$ are still relatively rare (at least compared to the large number of ICs), however, there is a rapidly growing number of crystals for which gas adsorption has been confirmed. Gas adsorption evidence for nanoporosity is compiled for a number of molecular crystals in Table 1. This can be combined with an analysis of their structures obtained from single crystal XRD characterisation and for this purpose it is useful to classify the free volume within a crystal by its interconnectivity. Hence formally non-porous crystals with isolated voids can be classified as zero-dimensional (0-D), those with linear channels as one-dimensional (1-D) and those with interconnecting channels penetrating along all three axes of the crystal as three-dimensional (3-D). ${ }^{109}$

\section{Dianin's compound and the lower limit of nanoporosity}

Inclusion compounds from 4-(4'-hydroxyphenyl)-2,2,4-trimethylchroman $\mathbf{2}$ have been recognised since Dianin's original research published in $1914^{110}$ and they have played an important role in the early studies of such materials due to the very large number of included guests that can be accommodated within its trigonal crystal structure. ${ }^{30,111-113}$ The crystal structures of ICs of 2 are remarkably invariant and are composed of a columnar arrangement of cages each formed by six host molecules held together by hydrogen-bonding. The void within the cage is hourglass-shaped with a maximum length of $11 \AA$ and maximum and minimum diameters of 6.5 and $4.4 \AA$, respectively. For all solvents, the inclusion compounds are true clathrates in that the guest molecules cannot be released without melting the crystal due to the very narrow channel (minimum diameter $=2.5 \AA$ ) that exists between the voids. The host can be crystallised in its unsolvated form, identical to the framework of the inclusion compounds, by sublimation or by using solvents whose molecules are too large to be incorporated into the voids (e.g. dodecane). ${ }^{81}$ This observation prompted an early study by Barrer and Shanson to assess the potential of this unsolvated molecular crystal as a "zeolitic-sorbent" for gases and vapours. ${ }^{26}$ It was shown that $\mathrm{Ar}, \mathrm{Kr}, \mathrm{Xe}, \mathrm{CO}_{2}, \mathrm{CH}_{4}, \mathrm{C}_{2} \mathrm{H}_{6}, \mathrm{C}_{3} \mathrm{H}_{8}, n-\mathrm{C}_{4} \mathrm{H}_{12}$, iso- $\mathrm{C}_{4} \mathrm{H}_{12}$, and neo- $\mathrm{C}_{5} \mathrm{H}_{12}$ could all be adsorbed. However, as molecular access to the voids is only through the interconnecting channels of minimum diameter $=2.5 \AA$, located at the ends of the hourglass-shaped voids, and that the smallest kinetic diameter of these adsorbates is $3.3 \AA$ (for $\mathrm{CO}_{2}$ ), ${ }^{114}$ it is likely that gas or vapour adsorption can only occur by a similar activated mechanism to that found for non-porous crystals of $\mathbf{1}$ involving

Table 1 Properties of the unsolvated crystals from 1 and $\mathbf{2}$ and the NMCs from compounds 3-19

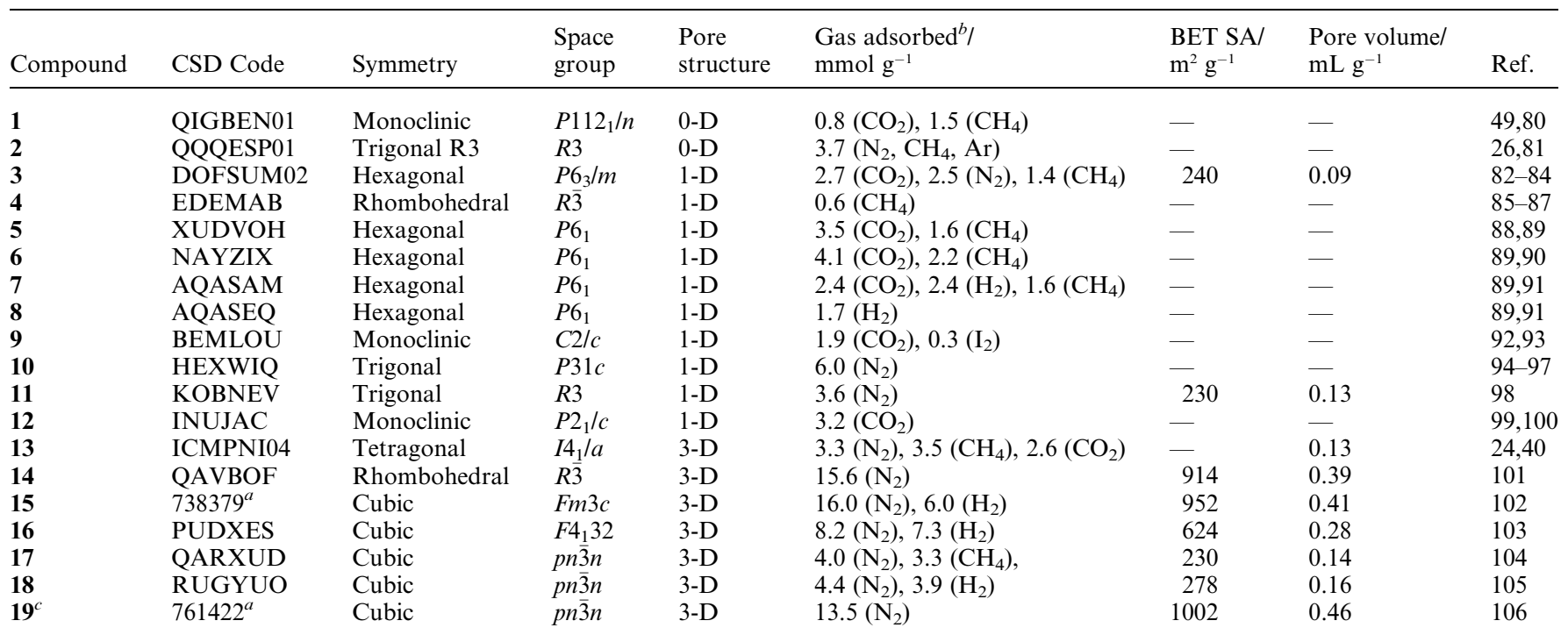

${ }^{a}$ Too recently submitted to have CDS codes assigned so submission numbers given. ${ }^{b} \mathrm{~N}_{2}$ and $\mathrm{H}_{2}$ measured at $77 \mathrm{~K}$; check references for temperature of adsorption used for other gases. ${ }^{c} \mathrm{M}=\mathrm{Fe}$ and $\mathrm{L}=\mathrm{PDIC}$ (see Fig. 2 for structure). 
dynamic processes. It is notable that Barrer and Shanson report that the kinetics of adsorption within the crystal are slow but that they can be enhanced by agitation (milling) using steel balls, which will reduce particle size and limit the distance through which the guest molecules have to permeate. ${ }^{26}$ It is clear that Dianin's compound falls on the boundary between a non-porous crystal (0-D) and a nanoporous crystal with linear channels (1-D).

\section{Molecular nanoporous crystals with 1-D channels}

The majority of NMCs, confirmed to date, possess 1-D channels (Table 1) and this nanopore topology is perhaps more easy to achieve in molecular crystals than in covalent materials or MOFs and provides a microporous organic analogy to the familiar mesoporous silicas that possess 1-D channels of hexagonal symmetry (e.g. MCM-41). ${ }^{115}$ Tris $(o$-phenylenedioxy)cyclotriphosphazene 3 (TPP, Fig. 2) occupies a special place in the development of NMCs as its crystals were the first to be unambiguously shown by Sozzani et al. to be nanoporous by a range of techniques including ${ }^{13} \mathrm{C}$ solid state NMR, ${ }^{116}$ laser polarised ${ }^{129} \mathrm{Xe} \mathrm{NMR},{ }^{70,117}$ and gas adsorption $\left(\mathrm{CO}_{2}\right.$ and $\left.\mathrm{CH}_{4}\right){ }^{83}$ TPP has long been known to act as the host for the formation of isostructural ICs that contain many different guests within one-dimensional channels of $6 \AA$ in diameter (Fig. 3). ${ }^{118,119}$ Removal of the included guest from the pseudohexagonal crystals (space group $=P 6_{3} / \mathrm{m}$ ) can result in the formation of a dense monoclinic crystal or, by careful treatment of the benzene-containing inclusion compound under vacuum, an unsolvated metastable form of the pseudo-hexagonal crystal is achieved. ${ }^{70,116}$ Sozzani et al. showed recently that macroscopic alignment of adsorbed Xe molecules within the NMC of $\mathbf{3}$ is possible as demonstrated by hyperpolarised Xe NMR. ${ }^{84}$

Similar 1-D channels to those of TPP, but which undulate between a maximum diameter of $6.4 \AA$ and minimum diameter of $5.3 \AA$, are found in the trigonal crystal (designated the $\beta$-form) of the ICs of bis(1,1,1-trifluoro-5,5-dimethyl-5-methoxy-acetylacetotato)copper(II) $4 .^{85-87,120,121}$ Although removal of the guest eventually results in a dense orthorhombic crystal ( $\alpha$-form), the unsolvated hexagonal crystals can be kinetically trapped due to the slow cis-to-trans isomerism required to obtain the $\alpha$-form. Exposure of the $\alpha$-form to organic vapours reforms the inclusion compound. Various hydrocarbons, including methane, are adsorbed by the unsolvated $\beta$-form, which is readily formed by the removal of methyl bromide from the inclusion compound. ${ }^{87}$

Several dipeptides, especially those derived from hydrophobic residues, possess permanent nanoporosity as demonstrated by He pycnometry and gas adsorption..$^{73,108,122-126}$ These include L-alanyl-L-valine 5, L-valyl-L-alanine 6, L-isoleucyl-L-valine 7 and L-valyl-L-isoleucyl 8, which form NMCs with cylindrical 1-D nanopores of diameters in the range 3.7-5.0 $\AA$ that can readily accommodate $\mathrm{CO}_{2}$ and $\mathrm{H}_{2}$ molecules. ${ }^{89}$ Other dipeptides crystallise with much larger channels, for example, those of L-phenylalanyl-L-phenylalanine are $\sim 10 \AA$ in diameter, but these have not been shown to possess permanent porosity to date. ${ }^{123}$

Other nanoporous molecular crystals with 1-dimensional channels include the unsolvated crystals derived from the natural product 2,2'-bis-(formyl-1,6,7-trihydroxy-5-isopropyl-3-methylnaphthalene (Gossypol) 9, which has been shown to adsorb gases $\left(\mathrm{CO}_{2}\right)^{93}$ and vapours (e.g., $\mathrm{I}_{2}$ and $\left.\mathrm{NH}_{3}\right)^{\cdot 92,127}$ 2,4,6-tris(4- bromophenoxy)1,3-triazine (BrPOT) 10, which contains large channels (diameter $=12 \AA$ ) and adsorbs $\mathrm{N}_{2}$ at $77 \mathrm{~K}$, although the isotherm has a non-conventional appearance; ${ }^{95,96}$ and the 1-D channel-containing inclusion compounds formed by the muchstudied host, 2,6-dimethylbicyclo[3.3.1]nonane-exo-2,exo-6diol, ${ }^{128}$ which shows convincing evidence of stability when unsolvated, however, this has not been confirmed by gas adsorption. ${ }^{129}$

A number of macrocycles align within crystals to give NMCs with 1-D channels, sometimes termed 'supramolecular nanotubes'. These include the family of torus-shaped cucurbit[n]urils $\left(n=5,6\right.$ and 8), ${ }^{130,131}$ for which gas adsorption studies of the crystal of cucurbit[6]uril 11 confirm nanoporosity, ${ }^{98}$ a bis-urea macrocycle 12 shown to adsorb $\mathrm{CO}_{2},{ }^{99,100}$ macrocycles aligned via calcogen-calcogen interactions, ${ }^{132}$ a macrocyclic dimer of a tetra-aryl-1,3-dioxolane-4,5-dimethanol (TADDOL) chiral ligand that in its unsolvated form can adsorb ether, ${ }^{133}$ azacalixarenes that adsorb $\mathrm{CO}_{2}$ selectively from air, ${ }^{134,135}$ and a number of metal-organic macrocycles formed through coordination chemistry, some of which demonstrate gas adsorption subsequent to removal of included solvent. ${ }^{76,136-143} \mathrm{~A}$ very recent paper describes a remarkable gallium-based 'molecular wheel' which has been shown to possess nanoporosity by hyperpolarized ${ }^{129} \mathrm{Xe}$ NMR. ${ }^{75}$

\section{Molecular nanoporous crystals with 3-D channels}

The most familiar topographic arrangement of void space with crystalline nanoporous materials, as possessed by most MOFs and zeolites, is a labyrinth of channels, which penetrate the crystal in all three dimensions. The voids at the points at which the channels intersect may possess much larger dimensions than the diameter of the interconnecting channels to produce a cagelike structure such as those found in zeolites. Such 3-D channel systems have also been found in a number of NMCs (Table 1) and have the advantage that permeation of gases may occur more rapidly than through a NMC with 1-D channels of similar diameter. ${ }^{144}$

The tetragonal $\beta$-form of the Werner complexes [M(4$\mathrm{MePy})_{4}(\mathrm{NCS})_{2}$, where $\mathrm{M}=\mathrm{a}$ metal cation] $\mathbf{1 3}$ has been known for sometime to form inclusion complexes with a wide variety of guests and that exchange of included solvent is possible. ${ }^{145,146}$ In the earliest report of a NMC, Allison and Barrer showed that the slow removal of included benzene from $\mathrm{Co}(4-\mathrm{MePy})_{4}(\mathrm{NCS})_{2}$, monitored by gravimetric measurement, occurred without significant change to the powder X-ray diffraction pattern and that subsequent exposure of the unsolvated complex to a range of gases (e.g. $\mathrm{N}_{2}, \mathrm{O}_{2}, \mathrm{CO}_{2}$ and $\mathrm{CH}_{4}$ ) and vapours showed rapid adsorption. ${ }^{24,25} \mathrm{~A}$ more recent study by Soldatov et al. has confirmed these findings and added more detail to the structures of the various crystal polymorphs of $13{ }^{40}$ The channel structure of the nanoporous $\beta$-form is described as possessing a distorted diamondoid topology with the guest molecules occupying the channels in between the four-way interconnecting voids.

Rigid molecular cages, constructed either with coordination $^{101,102,138,147-151}$ or covalent ${ }^{103}$ bonding, provide crystals with inherent voids. If the apertures of the cages are aligned within the crystal, channels are created and in some cases permanent nanoporosity results. Indeed crystals of the terthiophene-derived 


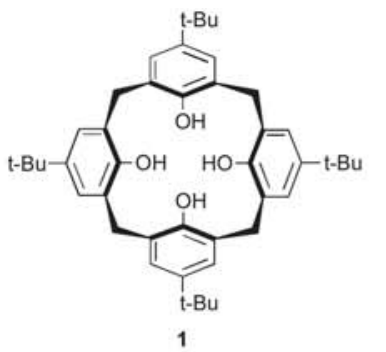<smiles>CC(N)C(=O)NC(C(=O)O)C(C)C</smiles>

5<smiles>Cc1cc2c(C(C)C)c(O)c(O)c(C=O)c2c(O)c1-c1c(C)cc2c(C(C)C)c(O)c(O)c(C=O)c2c1O</smiles>

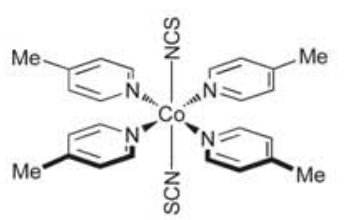

13<smiles>CC1(C)CC(C)(c2ccc(O)cc2)c2ccccc2O1</smiles>

2<smiles>CC(NN(C(=O)C(N)C(C)C)C(C)C)C(=O)O</smiles><smiles>Brc1ccc(Oc2nc(Oc3ccc(Br)cc3)nc(Oc3cccc(Br)c3)n2)cc1</smiles>

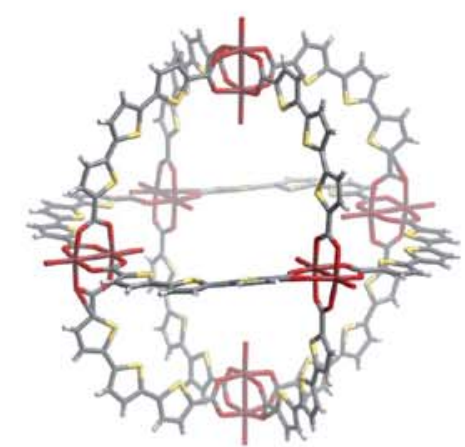

14

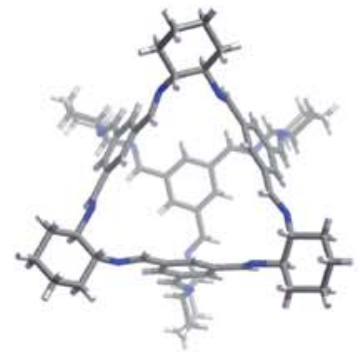

16
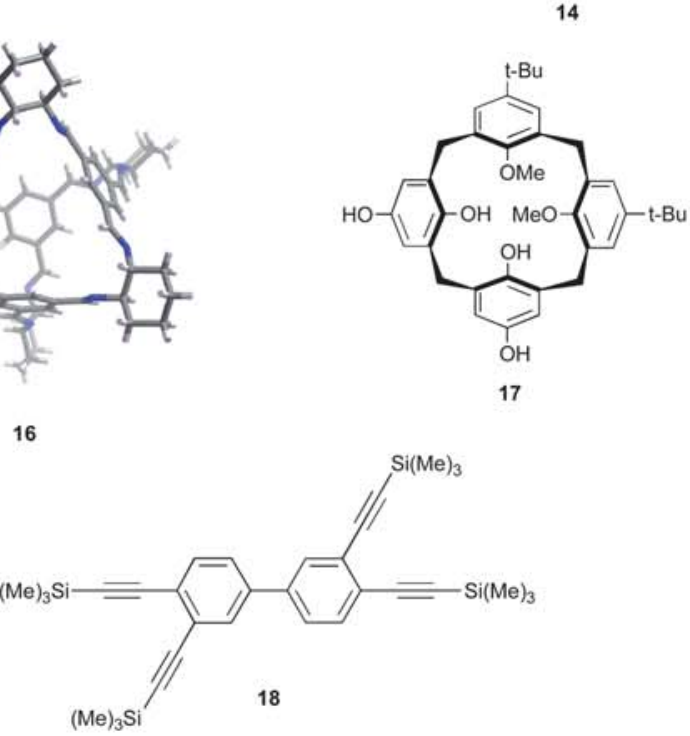<smiles>c1ccc2c(c1)OP1(=NP3(=NP4(=N1)Oc1ccccc1O4)Oc1ccccc1O3)O2</smiles>

3<smiles>CCC(C)C(N)C(=O)N(C)C(C(=O)O)C(C)C</smiles>

11

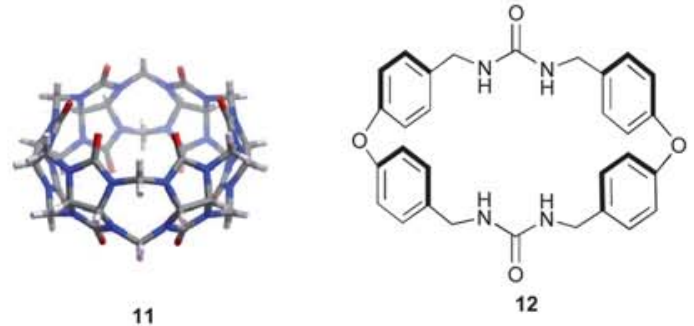<smiles></smiles><smiles>CCC(C)C(NC(=O)C(N)C(C)C)C(=O)O</smiles>
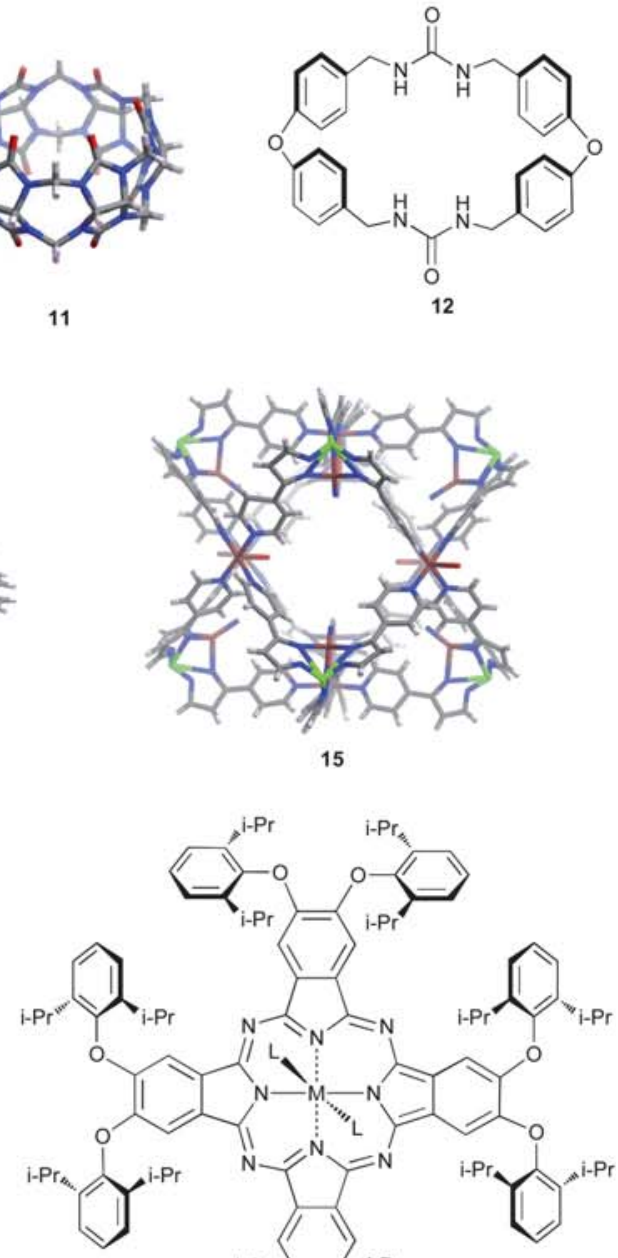

15
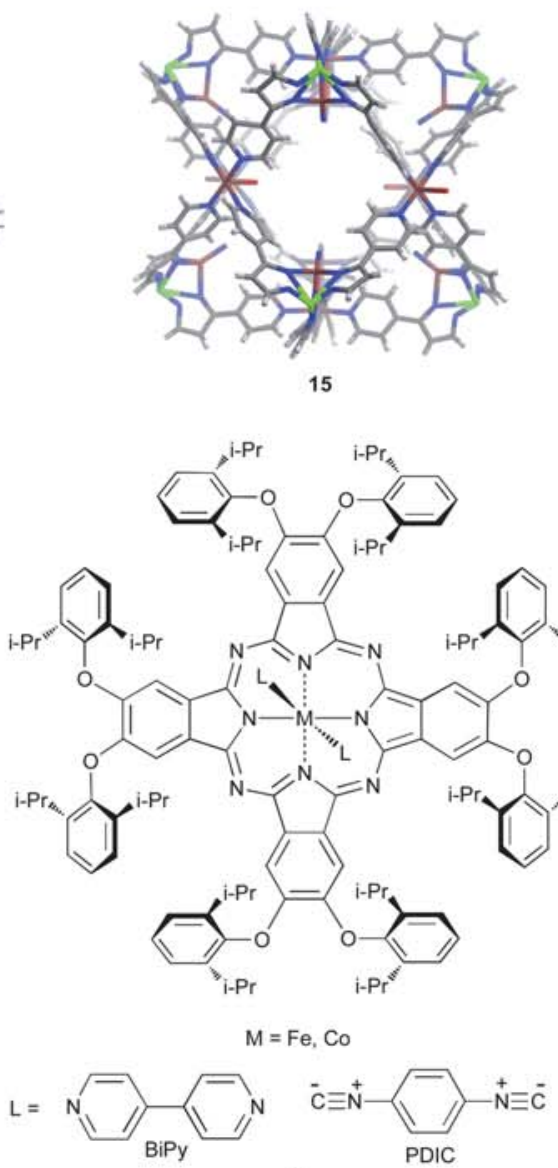

19

Fig. 2 Molecular structures of compounds 1-19. 


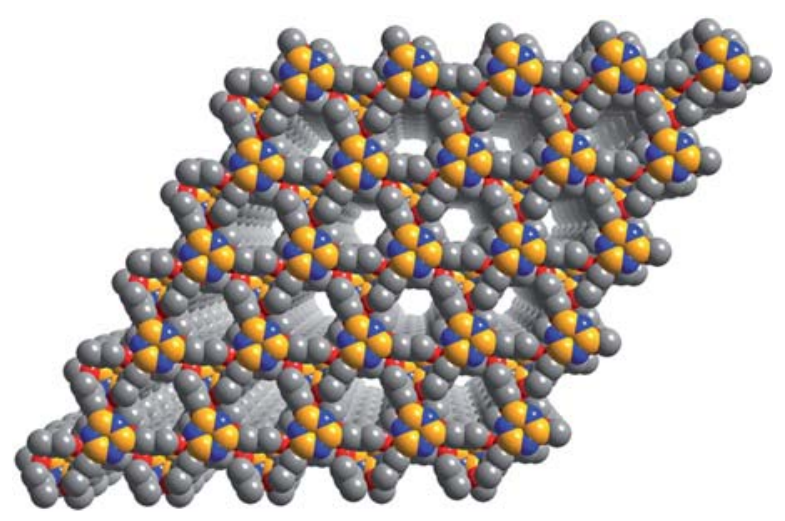

Fig. 3 A perspective view of the crystal structure of the extensively studied 1-D channel NMC formed from TPP (3).

"Metal-Organic Polyhedron" (MOP) 14 reported by Yaghi et al.;01 the "supramolecular nanoball" $\mathbf{1 5}$ prepared by the transition metal coordination of tris[3-(4'-pyridyl)pyrazol-1yl]hydroborate reported by Batten et $a l . ;^{102}$ and the purely organic cages described by Cooper et al. ${ }^{103}$ demonstrate amongst the greatest amount of nanoporosity for any NMCs studied to date (Table 1). Cooper's tetrahedral organic cages, (e.g. "cage 3" 16) which are assembled by rapidly reversible imine bond formation, are notable because their crystal packing can result in $0-\mathrm{D}, 1-\mathrm{D}$ or $3-\mathrm{D}$ void interconnectivity, depending upon the structure of the cage and the solvent of recrystallisation.

The unusual $p n \overline{3} n$ crystal space group, of cubic symmetry, is characterised by large units cells containing many molecular components and is uncommonly encountered for molecular crystals. However, in recent years it has provided three confirmed NMCs with complex 3-D channel structures. ${ }^{104-106}$ The first of these NMCs to be assessed for permanent nanoporosity, by Tedesco et al., was that derived from 1,2-dimethoxy-4-tertbutylcalix[4]dihydroquinone $\mathbf{1 7}$, which crystallises to give a hexameric assembly that packs to form two distinct types of void space: one a 3-D network of channels with minimum and maximum diameters of 3.9 and $8.5 \AA$, respectively, and the other composed of large spherical cages of $11.2 \AA$ in diameter interconnected by very narrow channels $(2.2 \AA) .{ }^{152}$ On removal of the included water, $\mathrm{N}_{2}, \mathrm{CH}_{4}$ and $\mathrm{CO}_{2}$ have been shown to be adsorbed by this NMC (Table 1) and a recent powder diffraction study located the adsorbed $\mathrm{CH}_{4}$ molecules within the channels. ${ }^{153}$

The NMC derived from 3,3',4,4'-tetra(trimethylsilylethynyl)biphenyl 18 was discovered by a targeted search of lowdensity crystals derived from rigid aromatic molecules within the CSD. ${ }^{105}$ In order to investigate this intriguing crystal, we resynthesised 18 and recrystallised it from hexane. XRD confirmed that the same $p n \overline{3} n$ crystal structure as that previously deposited in the CSD was obtained, within which 18 self-assembles into supramolecular macrocyclic tetramers with each molecule being held in place by 8 mutual $\mathrm{CH}-\pi$ interactions. ${ }^{105}$ These tetramers pack within the crystal to provide narrow channels $(\sim 4 \AA$ in diameter) that interconnect large voids $(\sim 11 \AA$ in diameter $)$. The resulting bicontinuous 3D nanopore structure (Fig. 4), a Schwartz $P$ minimal surface, ${ }^{154}$ is highly reminiscent of that of some zeolites (e.g. zeolite A). XRD analysis found that the crystal structure is retained after the included hexane is rapidly (a)
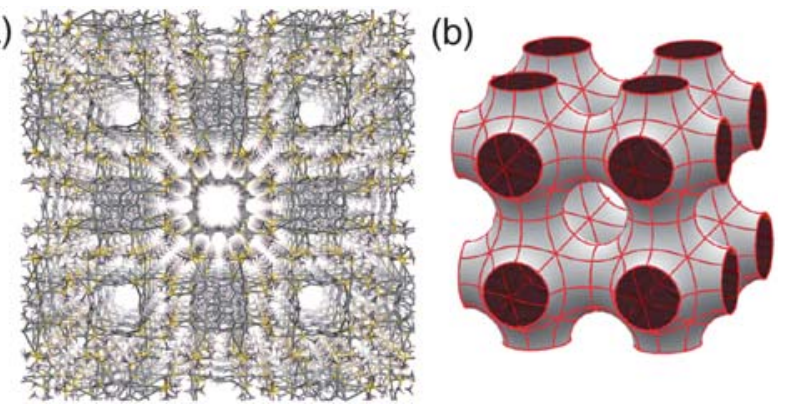

Fig. 4 (a) A perspective view of the structure of the 3-D channel NMC formed by 18 and (b) the Schwartz $P$ minimal surface, which has the same topological features as the micropore structure of the NMC. ${ }^{105}$

lost in a stream of air or by application of a vacuum. $\mathrm{N}_{2}$ adsorption confirmed that the crystals possess permanent nanoporosity (Table 1). Application of the Horvath-Kawazoe model ${ }^{155}$ to the low pressure $\mathrm{N}_{2}$ adsorption data mapped the pore-size distribution, which was consistent with the crystal structure. This NMC also adsorbs a significant quantity of $\mathrm{H}_{2}$ at $77 \mathrm{~K}$.

The molecular crystals of the metal complexes of $2,3,9,10,16,17,23,24$-octa( $\left(2^{\prime}, 6^{\prime}\right.$-di-iso-propylphenoxy)-phthalocyanine 19 belong to the $p n \overline{3} n$ space group and contain very large $\left(8 \mathrm{~nm}^{3}\right)$ solvent-filled voids. ${ }^{156}$ In addition to the zinc complex, which was a serendipitous discovery, we found that many other metal complexes of this phthalocyanine derivative $\left(\mathrm{M}=\mathrm{Mg}^{2+}, \mathrm{Al}^{3+}, \mathrm{Ti}^{4+}, \mathrm{Mn}^{2+}, \mathrm{Fe}^{2+}, \mathrm{Co}^{2+}, \mathrm{Zn}^{2+}, \mathrm{Ru}^{2+}\right.$ and $\left.\mathrm{In}^{3+}\right)$ form isomorphous crystals even with great variation in size, shape, type and number of axial ligand. The void structure of these Phthalocyanine Nanoporous Crystals (PNCs) resembles Schoen's I-WP triply periodic minimal surface in which free volume is unequally partitioned between two interpenetrating labyrinths by a non-self-intersecting, two-sided surface (Fig. 5). ${ }^{154}$ The larger labyrinth is composed of the $8 \mathrm{~nm}^{3}$ voids inside the cubic assembly of six phthalocyanines and the interconnecting channels located at each corner of the assembly; the smaller labyrinth is composed of the narrow interconnecting cavities that lie between the assemblies. The original solvent of recrystallisation within the PNCs can be rapidly and reversibly exchanged with other solvents. Of greater interest, rapid exchange of the axial ligands by a singlecrystal-to-single-crystal (SCSC) transformation is readily achieved. This exchange of axial ligands suggested the possibility that bidentate ligands of an appropriate length $(\sim 1 \mathrm{~nm})$ might bind simultaneously to two metal cations across the cavity, thus forming a bridge between adjacent hexa-phthalocyanine assemblies. This outcome was achieved with surprising ease by the SCSC addition of either 4,4'-bipyridyl (bipy) or 1,4-phenylenediisocyanide (PDIC) to the cobalt- or iron-containing NMCs. XRD analysis confirmed the retention of the crystal structures on addition of these 'wall-ties' and nitrogen adsorption and their permanent nanoporosity (Table 1). ${ }^{106}$ The molecular wall-ties bridge two phthalocyanines to form a dimeric complex, rather than forming an extended framework; therefore, these Phthalocyanine Unsolvated Nanoporous Crystals (PUNCs) are still molecular crystals rather 
(a)

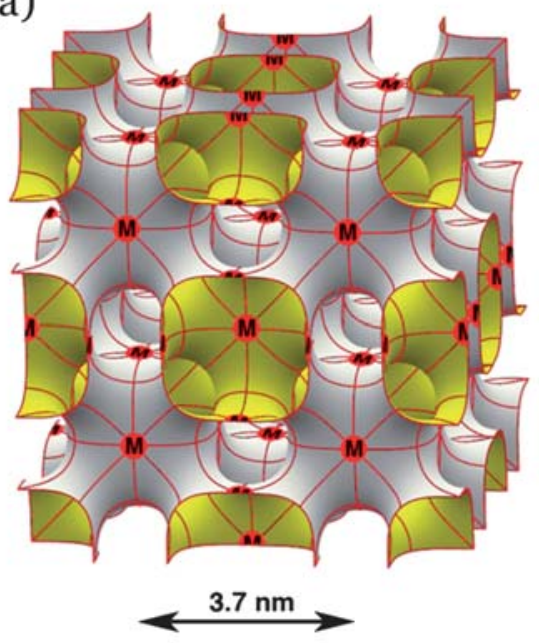

(b)

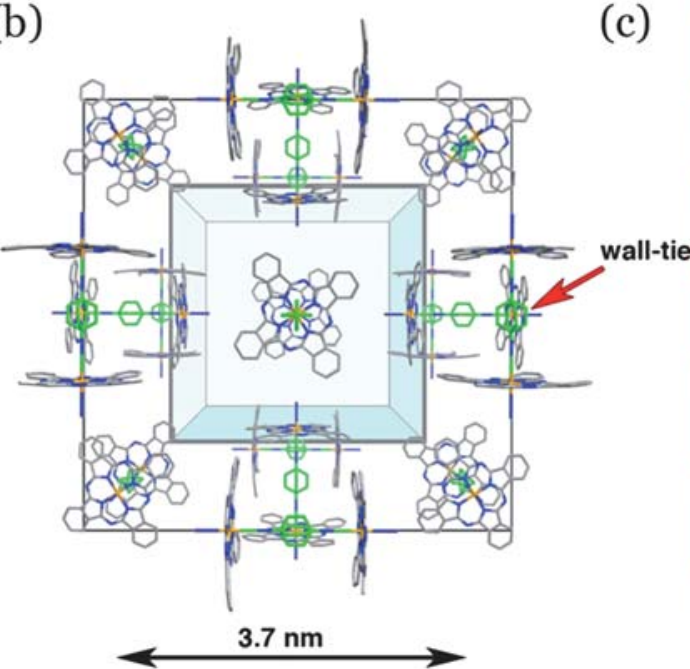

(c)

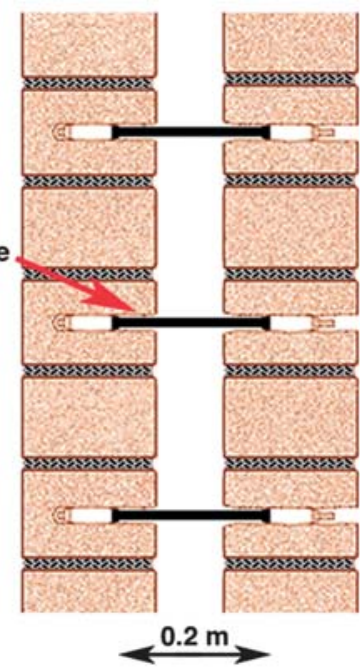

Fig. 5 (a) The nanoporous structure of the NMC formed by 19 as represented by Schoen's I-WP triply periodic minimal surface with the transition metals denoted as M. (b) The single crystal XRD structure of the NMC from 19 ( $\mathrm{M}=\mathrm{Fe}^{2+}$ and $\mathrm{L}=\mathrm{PDIC}$ ). (c) A cross-section through a cavity brick wall showing the role of wall ties in maintaining stability. The location of the bidentate ligand 'molecular wall tie' within the cavity of the NMC is indicated. ${ }^{106}$

than MOFs. This concept could be extended to many different metal cations and other bidentate ligands. In addition, the analogous octaazaphthalocyanine provides PNCs and could be used to provide catalytic PUNCs of different reactivities. ${ }^{157}$

\section{Conclusions}

In the context of the above survey of NMCs, can the requirements for the attainment of permanent nanoporosity in molecular crystals be defined? Certainly, it is difficult to perceive obvious structural trends from the disparate molecular structures 1-19. In general, ICs are formed from molecules that possess awkward shapes, or in some cases from molecules that form supramolecular assemblies of awkward shapes, which do not pack efficiently in crystals. An awkward shape can be a macrocycle, a nanotube, a cage, or simply a molecular structure that possesses concave faces so that space-efficient packing is difficult due to the mutual impenetrability of internal free volume (i.e., these molecules or assemblies have a large surface area relative to the total volume that they occupy). As an alternative to crystallisation such molecules may form an amorphous glass with what has been termed 'intrinsic microporosity'. ${ }^{158,159}$ However, the requirement of the crystal to compensate for inefficient packing by the incorporation of solvent molecules explains only why these molecules form ICs but not why these particular ICs are more stable than others to the removal of the guest solvent.

Solvent removal can cause several nano-scale or macroscopic changes in crystal structure. Firstly, a rapid transformation to a denser crystal form can occur (Fig. 1a) as in the well-studied ICs based on urea. ${ }^{35}$ However, the occurrence of a denser crystal form does not prohibit NMC formation as the molecular components 3, 4, 10, 13 and 17 all possess high density crystal forms but, by careful extraction of solvent from their IC, a metastable NMC can be obtained (Fig. 1d). Secondly, the removal of solvent may cause internal stress to the crystal so that fragmentation results to give a microcrystalline material
(Fig. 1e). This stress results from a reduction of the volume of the unit cell and the differential loss of solvent closer to the surface of the crystal. It seems likely that crystals of cubic symmetry may be more stable towards solvent loss than 1D channel structures due to enhanced stress distribution. ${ }^{160}$ Fragmentation is often apparent by a macroscopic change in appearance of the crystal and the inability to obtain single crystal XRD data. However, fragmentation does not necessarily mean that the packing of the host within the unsolvated crystal is markedly different from that of the inclusion compound or that it is not nanoporous. Hence, it is possible that some crystals have not been recognised as NMCs simply because their unsolvated structure cannot be confirmed by single crystal XRD. More widespread use of powder XRD, gas adsorption analysis and hyperpolarised ${ }^{129} \mathrm{Xe}$ NMR may reveal that a greater proportion of inclusion compounds form NMCs. ${ }^{76,134,139}$

Generally, ICs in which solvent molecules are strongly bound to the host framework, and thus contribute greatly towards the overall stability of the crystal, do not survive evacuation. ${ }^{32}$ Indeed most of the confirmed NMCs listed in Table 1 are formed from ICs that contain non-polar solvents, which would not be expected to interact strongly with the crystal and the resulting internal surfaces within the NMCs are relatively non-polar and hydrophobic (however, there are some possible exceptions where $\mathrm{H}$-bonding forms highly polar channels within apparently robust crystals ${ }^{161-165}$ ). For example, a recent study by Tedesco and coworkers shows that the cubic IC precursor to the NMC of calixarene $\mathbf{1 7}$ forms only in the presence of relatively non-polar solvents (e.g. chloroform) whereas another IC compound, without a porous channel structure, is formed from more polar solvents (e.g. acetonitrile). ${ }^{166}$ Similarly one of the covalent cages reported by Cooper et al. gives a non-porous crystal (0-D porosity) when recrystallised from polar ethyl acetate but a porous crystal (3-D porosity) when crystallised from a relatively non-polar solvent mixture of toluene and dichloromethane. ${ }^{103}$ The tight binding of solvent molecules may explain 
why the many beautifully designed H-bonded open framework crystals $^{167-170}$ appear less stable to solvent removal than the NMCs described above, most of which were discovered serendipitously and possess a crystal 'framework' that is held together only by much weaker intermolecular forces (e.g. $\mathrm{CH}-\pi$ and dispersion forces). It is notable for those NMCs composed of molecules with strongly $\mathrm{H}$-bonding functional groups (i.e. 1, 2, 5-7, 9, 11, 12 and 17) that these interactions are generally deployed to make supramolecular structures such as macrocycles, nanotubes or cages rather than to provide an extended framework and that strong $\mathrm{H}$-bonding does not occur between the host and the included solvent. In addition, it is possible that the instability of some of the H-bonded open framework crystals is due to the extremely low proportion of the total volume of the crystals that are occupied by the host framework $(<30 \%)$ so that these single-walled structures, unlike the double-walled structures of most NMCs, require stabilisation by the solvent. ${ }^{\mathbf{1 6 8 , 1 7 0}}$

With emerging potential applications as molecular sieves, ${ }^{\mathbf{1 0 8}}$ the active component of sensors, ${ }^{171}$ biodegradable nanoporous materials, ${ }^{124}$ catalysts, ${ }^{67,106}$ nanoscale reaction flasks, ${ }^{42,172-175}$ adsorbents for radioactive vapour ${ }^{176}$ and as hydrogen $89,103,105$ or methane $\mathbf{8 3 , 8 9 , 1 5 3}^{3}$ storage materials, there is a clear incentive to identify new NMCs. Unfortunately, the prediction of the structure of molecular crystals still represents one of the most difficult challenges in science and this is particularly true when dealing with relatively complex molecules which pack together using weak intermolecular interactions such as those which seem to be successful at forming NMCs. ${ }^{17}$ With more than one molecular component, as is the case for the precursor ICs, it becomes impossible. ${ }^{177,178}$ Therefore, it is likely that most new NMCs will continue to be obtained by serendipitous discovery rather than by design, although some design can be used to direct the chemical synthesis of novel macrocycles or cage structures or suggest simple modifications to molecular systems that form robust crystal structures (e.g., placing different metal cations in 19, exchanging ligands, etc.). A few years ago it was determined that there were $85000 \mathrm{ICs}$ in the $\mathrm{CSD}^{27}$ from a total of around 400000 structures. There will be many more today as the total number of structures in the CSD now exceeds $500000 .{ }^{179}$ An intriguing question is how many of these ICs could be precursors to NMCs? Targeted searches of the CSD can identify known ICs that are potential precursors to NMCs with interesting structures. For example, we looked for low-density crystals $\left(<0.9 \mathrm{~g} \mathrm{~mL}^{-1}\right)$ derived from rigid aromatic compounds and identified 23 candidate crystals structures, ${ }^{180}$ of which only one was selected for full reassessment (18, BALMIN), due to its marked resemblance to the structure of a zeolite. ${ }^{105}$ It proved clear from the smaller unit cell of the unsolvated crystal of $\mathbf{1 8}$ that the originally deposited structure contained disordered hexane and was, therefore, a good example of a crystal with what Barbour calls 'virtual nanoporosity', ${ }^{46}$ i.e. apparent porosity due to included solvent molecules being ignored or removed during XRD data processing. It is likely that most of the other 22 candidate structures possess only virtual nanoporosity but some could, like 18, also yield NMCs if assessed by gas adsorption. This use of low density as a search criterion for the identification of potential NMCs is severely limited because XRD analysis of an IC usually locates ordered solvent molecules within its void structure that will often increase the density of the crystal. Even the presence of highly disordered solvent is often accounted for by measuring the electron count in apparent voids using software programs such as SQUEEZE, which will also be reflected in the reported density. So more sophisticated criteria for searching the CSD are required, but more importantly, it will require the motivation to take a risk in re-making a known compound for which there may only be a small chance of establishing a new NMC. This risk is only worth taking if the potential NMC can provide some enhancement over existing examples. Clearly, it would be foolishly optimistic to place any emphasis on our current $100 \%$ success rate of re-examining existing IC structures in the CSD (based on a sample of one!). Nevertheless, even if only a few percent of these ICs are stable towards solvent removal, it is likely that several thousand potential NMCs are ready to be discovered.

\section{Acknowledgements}

I thank Dr C. Grazia Bezzu and Dr Kadhum J. Msayib for their valuable contributions to the understanding of NMCs and EPSRC (EP/F019114/1) for funding.

\section{Notes and references}

1 J. Fraxedas, Molecular Organic Materials, CUP, Cambridge, 2006.

2 J. Lee, O. K. Farha, J. Roberts, K. A. Scheidt, S. T. Nguyen and J. T. Hupp, Chem. Soc. Rev., 2009, 38, 1450.

3 L. J. Murray, M. Dinca and J. R. Long, Chem. Soc. Rev., 2009, 38, 1294.

4 R. E. Morris and P. S. Wheatley, Angew. Chem., Int. Ed., 2008, 47, 4966.

5 M. E. Davis, Nature, 2002, 417, 813.

6 P. A. Wright, Microporous Framework Solids, RSC, Cambridge, 2007.

7 D. J. Plaut, K. T. Holman, A. M. Pivovar and M. D. Ward, J. Phys. Org. Chem., 2000, 13, 858.

8 K. E. Maly, J. Mater. Chem., 2009, 19, 1781.

9 H. Li, M. Eddaoudi, M. O'Keeffe and O. M. Yaghi, Nature, 1999, 402, 276 .

10 G. Ferey, Chem. Soc. Rev., 2008, 37, 191.

11 N. W. Ockwig, O. Delgado-Friedrichs, M. O'Keeffe and O. M. Yaghi, Acc. Chem. Res., 2005, 38, 176.

12 G. Ferey, C. Mellot-Draznieks, C. Serre, F. Millange, J. Dutour, S. Surble and I. Margiolaki, Science, 2005, 309, 2040.

13 G. Ferey, C. Mellot-Draznieks, C. Serre and F. Millange, Acc. Chem. Res., 2005, 38, 217.

14 O. M. Yaghi, M. O'Keefe, N. W. Ockwig, H. K. Chae, M. Eddaoudi and J. Kim, Nature, 2003, 423, 705.

15 S. Kitagawa, R. Kitaura and S. Noro, Angew. Chem., Int. Ed., 2004, 43, 2334.

16 G. Couderc and J. Hulliger, Chem. Soc. Rev., 2010, 39, 1545.

17 J. D. Dunitz and A. Gavezzotti, Chem. Soc. Rev., 2009, 38, 2622.

18 J. D. Dunitz, G. Filippini and A. Gavezzotti, Helv. Chim. Acta, 2000, 83, 2317.

19 B. F. Hoskins and R. Robson, J. Am. Chem. Soc., 1990, 112, 1546.

20 B. F. Abrahams, B. F. Hoskins, D. M. Michail and R. Robson, Nature, 1994, 369, 727.

21 R. Robson, Dalton Trans., 2008, 5113.

22 M. Kondo, T. Yoshitomi, K. Seki, H. Matsuzaka and S. Kitagawa, Angew. Chem., Int. Ed. Engl., 1997, 36, 1725.

23 H. Li, M. Eddaoudi, T. L. Groy and O. M. Yaghi, J. Am. Chem. Soc., 1998, 120, 8571.

24 S. A. Allison and R. M. Barrer, J. Chem. Soc. A, 1969, 1717.

25 R. M. Barrer, Adv. Chem., 1973, 121, 1.

26 R. M. Barrer and V. H. Shanson, J. Chem. Soc., Chem. Commun., 1976, 333.

27 J. van de Streek, CrystEngComm, 2007, 9, 350.

28 J. L. Atwood, J. E. D. Davies and D. D. MacNichol, Inclusion Compounds, Academic Press, London, 1984/1991. 
29 F. H. Herbstein, Crystalline Molecular Complexes and Compounds, Oxford University Press, Oxford, 2005.

30 Y. A. Dyadin, I. S. Terekhova, T. V. Rodionova and D. V. Soldatov, J. Struct. Chem., 1999, 40, 645.

31 C. Dawson, P. N. Horton, M. B. Hursthouse and S. L. James, CrystEngComm, 2010, 12, 1048.

32 L. R. Nassimbeni, Acc. Chem. Res., 2003, 36, 631.

33 L. R. Nassimbeni and M. L. Kilkenny, J. Chem. Soc., Dalton Trans., $2001,1172$.

34 K. Endo, T. Sawaki, M. Koyanagi, K. Kobayashi, H. Masuda and Y. Aoyama, J. Am. Chem. Soc., 1995, 117, 8341.

35 K. D. M. Harris, Supramol. Chem., 2007, 19, 47.

36 Y. Aoyama, Top. Curr. Chem., 1998, 198, 131.

37 P. J. Langley and J. Hulliger, Chem. Soc. Rev., 1999, 28, 279.

38 E. Zass, D. A. Plattner, A. K. Beck and M. Neuburger, Helv. Chim. Acta, 2002, 85, 4012.

39 W. Li, G. Gahungu, J. Zhang and L. Hao, J. Phys. Chem. B, 2009, 113, 16472 .

40 D. V. Soldatov, G. D. Enright and J. A. Ripmeester, Cryst. Growth Des., 2004, 4, 1185.

41 K. Yoshizawa, S. Toyota, F. Toda, M. Kato and I. Csoregh, CrystEng Comm, 2007, 9, 786.

42 J. Yang, M. B. Dewal and L. S. Shimizu, J. Am. Chem. Soc., 2006, 128, 8122 .

43 M. Bucknum and E. A. Castro, J. Math. Chem., 2006, 39, 611.

44 T. Sawaki and Y. Aoyama, J. Am. Chem. Soc., 1999, 121, 4793.

45 IUPAC notation suggests that micropores have a diameter less than $2 \mathrm{~nm}$, mesopores have diameters in the range 20-50 nm and macropores have diameters greater than $50 \mathrm{~nm}$. Nanopores are not defined but generally have diameters less than $50 \mathrm{~nm}$.

46 L. J. Barbour, Chem. Commun., 2006, 1163.

47 T. J. Burchell, G. D. Enright and J. A. Ripmeester, New J. Chem., 2008, 32, 864 .

48 P. Brunet, M. Simard and J. D. Wuest, J. Am. Chem. Soc., 1997, 119, 2737.

49 J. L. Atwood, L. J. Barbour and A. Jerga, Angew. Chem., Int. Ed., 2004, 43, 2948.

50 J. L. Atwood, L. J. Barbour, P. K. Thallapally and T. B. Wirsig, Chem. Commun., 2005, 51.

51 S. J. Dalgarno, P. K. Thallapally, L. J. Barbour and J. L. Atwood, Chem. Soc. Rev., 2007, 36, 236.

52 J. L. Daschbach, P. K. Thallapally, J. L. Atwood, B. P. McGrail and L. X. Dang, J. Chem. Phys., 2007, 127.

53 P. K. Thallapally, B. P. McGrail, S. J. Dalgarno, H. T. Schaef, J. Tian and J. L. Atwood, Nat. Mater., 2008, 7, 146.

54 P. K. Thallapally, T. B. Wirsig, L. J. Barbour and J. L. Atwood, Chem. Commun., 2005, 4420.

55 D. H. Brouwer, I. L. Moudrakovski, K. A. Udachin, G. D. Enright and J. A. Ripmeester, Cryst. Growth Des., 2008, 8, 1878.

56 G. D. Enright, K. A. Udachin, I. L. Moudrakovski and J. A. Ripmeester, J. Am. Chem. Soc., 2003, 125, 9896.

57 J. A. Ripmeester, G. D. Enright, C. I. Ratcliffe, K. A. Udachin and I. L. Moudrakovski, Chem. Commun., 2006, 4986.

58 K. A. Udachin, I. L. Moudrakovski, G. D. Enright, C. I. Ratcliffe and J. A. Ripmeester, Phys. Chem. Chem. Phys., $2008,10,4636$.

59 J. G. Wijmans and R. W. Baker, J. Membr. Sci., 1995, 107, 1.

60 J. Tian, P. K. Thallapally, S. J. Dalgarno and J. L. Atwood, J. Am. Chem. Soc., 2009, 131, 13216.

61 M. Albrecht, M. Lutz, A. L. Spek and G. van Koten, Nature, 2000, 406, 970.

62 G. M. Espallargas, M. Hippler, A. J. Florence, P. Fernandes, J. van de Streek, M. Brunelli, W. I. F. David, K. Shankland and L. Brammer, J. Am. Chem. Soc., 2007, 129, 15606.

63 L. Dobrzanska, G. O. Lloyd, H. G. Raubenheimer and L. J. Barbour, J. Am. Chem. Soc., 2006, 128, 698.

64 D. Benito-Garagorri, M. Puchberger, K. Mereiter and K. Kirchner, Angew. Chem., Int. Ed., 2008, 47, 9142.

65 S. Takamizawa and M. A. Kohbara, Dalton Trans., 2007, 3640.

66 A. Lennartson, M. Hakansson and S. Jagner, New J. Chem., 2007, 31, 344 .

67 H. Zheng, P. S. White and M. Brookhart, Nature, 2010, 465, 598.

68 A. W. Thornton, T. Hilder, A. J. Hill and J. M. Hill, J. Membr. Sci., 2009, 336, 101.
69 J. Rouquerol, F. Rouquerol and K. W. Sing, Adsorption by Powders and Porous Solids: Principles, Methodology and Applications, Academic Press, London, 1999.

70 P. Sozzani, A. Comotti, R. Simonutti, T. Meersmann, J. W. Logan and A. Pines, Angew. Chem., Int. Ed., 2000, 39, 2695.

71 A. V. Nossov, D. V. Soldatov and J. A. Ripmeester, J. Am. Chem. Soc., 2001, 123, 3563.

72 K. J. Ooms, K. Campbell, R. R. Tykwinski and R. E. Wasylishen, J. Mater. Chem., 2005, 15, 4318.

73 D. V. Soldatov, I. L. Moudrakovski, E. V. Grachev and J. A. Ripmeester, J. Am. Chem. Soc., 2006, 128, 6737.

74 D. H. Brouwer, S. Alavi and J. A. Ripmeester, Phys. Chem. Chem. Phys., 2007, 9, 1093.

75 C. Y. Cheng, T. C. Stamatatos, G. Christou and C. R. Bowers, J. Am. Chem. Soc., 2010, 132, 5387.

76 K. Campbell, K. J. Ooms, R. E. Wasylishen and R. R. Tykwinski, Org. Lett., 2005, 7, 3397.

77 C. Y. Cheng and C. R. Bowers, J. Am. Chem. Soc., 2007, 129, 13997.

78 M. Dinca and J. R. Long, J. Am. Chem. Soc., 2005, 127, 9376.

79 D. N. Dybtsev, H. Chun, S. H. Yoon, D. Kim and K. Kim, J. Am. Chem. Soc., 2004, 126, 32.

80 J. L. Atwood, L. J. Barbour, A. Jerga and B. L. Schottel, Science, 2002, 298, 1000 .

81 F. Imashiro, M. Yoshimura and T. Fujiwara, Acta Crystallogr., Sect. C: Cryst. Struct. Commun., 1998, 54, 1357.

82 G. Couderc, T. Hertzsch, N. R. Behrnd, K. Kramer and J. Hulliger, Microporous Mesoporous Mater., 2006, 88, 170.

83 P. Sozzani, S. Bracco, A. Comotti, L. Ferretti and R. Simonutti, Angew. Chem., Int. Ed., 2005, 44, 1816.

84 A. Comotti, S. Bracco, L. Ferretti, M. Mauri, R. Simonutti and P. Sozzani, Chem. Commun., 2007, 350.

85 D. V. Soldatov, J. A. Ripmeester, S. I. Shergina, I. E. Sokolov, A. S. Zanina, S. A. Gromilov and Y. A. Dyadin, J. Am. Chem. Soc., 1999, 121, 4179.

86 A. Y. Manakov, D. V. Soldatov, J. A. Ripmeester and J. Lipkowski, J. Phys. Chem. B, 2000, 104, 12111.

87 D. V. Soldatov and J. A. Ripmeester, Chem. Mater., 2000, 12, 1827.

88 C. H. Gorbitz, Acta Crystallogr., Sect. B: Struct. Sci., 2002, 58, 849.

89 A. Comotti, S. Bracco, G. Distefano and P. Sozzani, Chem. Commun., 2009, 284.

90 C. H. Gorbitz, CrystEngComm, 2005, 7, 670.

91 C. H. Gorbitz, New J. Chem., 2003, 27, 1789.

92 S. A. Talipov, B. T. Ibragimov, F. Kh, Z. G. Tiljakov, A. J. Blake, T. Hertzsch and J. Hulliger, J. Inclusion Phenom. Macrocyclic Chem., 2007, 59, 287.

93 T. Le Roex and L. R. Nassimbeni, Acta Crystallogr., Sect. A: Found. Crystallogr., 2006, 62, s225.

94 K. Reichenbacher, H. I. Suss, H. Stoeckli-Evans, S. Bracco, P. Sozzani, E. Weber and J. Hulliger, New J. Chem., 2004, 28, 393.

95 H. I. Suss and J. Hulliger, Microporous Mesoporous Mater., 2005, 78, 23.

96 K. Reichenbacher, G. Couderc, A. Neels, K. Kramer, E. Weber and J. Hulliger, J. Inclusion Phenom. Macrocyclic Chem., 2008, 61, 127.

97 B. K. Saha, R. K. R. Jetti, L. S. Reddy, S. Aitipamula and A. Nangia, Cryst. Growth Des., 2005, 5, 887.

98 S. Lim, H. Kim, N. Selvapalam, K. J. Kim, S. J. Cho, G. Seo and K. Kim, Angew. Chem., Int. Ed., 2008, 47, 3352.

99 L. S. Shimizu, A. D. Hughes, M. D. Smith, M. J. Davis, B. P. Zhang, H. C. zur Loye and K. D. Shimizu, J. Am. Chem. Soc., 2003, 125, 14972.

100 M. B. Dewal, M. W. Lufaso, A. D. Hughes, S. A. Samuel, P. Pellechia and L. S. Shimizu, Chem. Mater., 2006, 18, 4855.

101 Z. Ni, A. Yassar, T. Antoun and O. M. Yaghi, J. Am. Chem. Soc., $2005, \mathbf{1 2 7}, 12752$.

102 M. B. Duriska, S. M. Neville, J. Z. Lu, S. S. Iremonger, J. F. Boas, C. J. Kepert and S. R. Batten, Angew. Chem., Int. Ed., 2009, 48, 8919.

103 T. Tozawa, J. T. A. Jones, S. I. Swamy, S. Jiang, D. J. Adams, S. Shakespeare, R. Clowes, D. Bradshaw, T. Hasell, S. Y. Chong, C. Tang, S. Thompson, J. Parker, A. Trewin, J. Bacsa, A. M. Z. Slawin, A. Steiner and A. I. Cooper, Nat. Mater., 2009, 8, 973.

104 P. K. Thallapally, B. P. McGrail, J. L. Atwood, C. Gaeta, C. Tedesco and P. Neri, Chem. Mater., 2007, 19, 3355. 
105 K. J. Msayib, D. Book, P. M. Budd, N. Chaukura, K. D. M. Harris, M. Helliwell, S. Tedds, A. Walton, J. E. Warren, M. C. Xu and N. B. McKeown, Angew. Chem., Int. Ed., 2009, 48, 3273.

106 C. G. Bezzu, J. E. Warren, M. Helliwell, D. R. Allan and N. B. McKeown, Science, 2010, 327, 1627.

107 The kinetic diameters of $\mathrm{CO}_{2}, \mathrm{O}_{2}, \mathrm{~N}_{2}, \mathrm{Ar}$ and $\mathrm{CH}_{4}$ are 3.30, 3.46, $3.64,3.70$ and $3.82 \AA$, respectively.

108 R. V. Afonso, J. Durao, A. Mendes, A. M. Damas and L. Gales, Angew. Chem., Int. Ed., 2010, 49, 3034.

109 In theory, NMCs with 2-D pore structures are possible but none have been identified to date.

110 J. Dianin, J. Russ. Phys. Chem. Soc., 1914, 46, 1310.

111 H. M. Powell and B. D. P. Wetters, Chem. Ind., 1955, 61, 256.

112 W. Baker, A. J. Floyd, J. F. W. McOmie, G. Pope, A. S. Weaving and J. H. Wild, J. Chem. Soc., 1956, 2010.

113 L. Mandelcorn, N. N. Goldberg and R. E. Hoff, J. Am. Chem. Soc., 1960, 82, 3297.

114 S. Sircar, Ind. Eng. Chem. Res., 2006, 45, 5435.

115 J. S. Beck, J. C. Vartuli, W. J. Roth, M. E. Leonowicz, C. T. Kresge, K. D. Schmitt, C. T. W. Chu, D. H. Olson, E. W. Sheppard, S. B. McCullen, J. B. Higgins and J. L. Schlenker, J. Am. Chem. Soc., 1992, 114, 10834.

116 A. Comotti, R. Simonutti, S. Stramare and P. Sozzani, Nanotechnology, 1999, 10, 70.

117 T. Meersmann, J. W. Logan, R. Simonutti, S. Caldarelli, A. Comotti, P. Sozzani, L. G. Kaiser and A. Pines, J. Phys. Chem. $A, 2000,104,11665$.

118 H. R. Allcock, Acc. Chem. Res., 1978, 11, 81.

119 H. R. Allcock and L. A. Siegel, J. Am. Chem. Soc., 1964, 86, 5140.

120 D. V. Soldatov, E. V. Grachev and J. A. Ripmeester, Cryst. Growth Des., 2002, 2, 401.

121 D. V. Soldatov and J. A. Ripmeester, J. Inclusion Phenom. Macrocyclic Chem., 2001, 39, 81 .

122 C. H. Gorbitz, Chem.-Eur. J., 2001, 7, 5153.

123 C. H. Gorbitz, Chem.-Eur. J., 2007, 13, 1022.

124 S. Guha, T. Chakraborty and A. Banerjee, Green Chem., 2009, 11, 1139.

125 D. V. Soldatov, I. L. Moudrakovski and J. A. Ripmeester, Angew. Chem., Int. Ed., 2004, 43, 6308.

126 C. H. Gorbitz, Acta Crystallogr., Sect. B: Struct. Sci., 2010, 66, 84

127 S. A. Talipov, A. Manakov, B. T. Ibragimov, J. Lipkowski and Z. G. Tiljakov, J. Inclusion Phenom. Mol. Recognit. Chem., 1997, 29, 33.

128 R. Bishop, Acc. Chem. Res., 2009, 42, 67.

129 A. T. Ung, D. Gizachew, R. Bishop, M. L. Scudder, I. G. Dance and D. C. Craig, J. Am. Chem. Soc., 1995, 117, 8745.

130 D. Bardelang, K. A. Udachin, D. M. Leek and J. A. Ripmeester, CrystEngComm, 2007, 9, 973.

131 Y. Miyahara, K. Abe and T. Inazu, Angew. Chem., Int. Ed., 2002, 41, 3020.

132 R. Gleiter, D. B. Werz and B. J. Rausch, Chem.-Eur. J., 2003, 9, 2676.

133 D. A. Plattner, A. K. Beck and M. Neuburger, Helv. Chim. Acta, $2002,85,4000$.

134 H. Tsue, K. Ishibashi, S. Tokita, H. Takahashi, K. Matsui and R. Tamura, Chem.-Eur. J., 2008, 14, 6125.

135 H. Tsue, K. Matsui, K. Ishibashi, H. Takahashi, S. Tokita, K. Ono and R. Tamura, J. Org. Chem., 2008, 73, 7748.

136 C. Y. Su, X. P. Yang, B. S. Kang and T. C. W. Mak, Angew. Chem., Int. Ed., 2001, 40, 1725.

137 I. Kim, B. Kwak and M. S. Lah, Inorg. Chim. Acta, 2001, 317, 12.

138 M. J. Prakash and M. S. Lah, Chem. Commun., 2009, 3326.

139 C. Pariya, C. R. Sparrow, C. K. Back, G. Sandi, F. R. Fronczek and A. W. Maverick, Angew. Chem., Int. Ed., 2007, 46, 6305.

140 J. Y. An, R. P. Fiorella, S. J. Geib and N. L. Rosi, J. Am. Chem. Soc., 2009, 131, 8401.

141 B. Chatterjee, J. C. Noveron, M. J. E. Resendiz, J. Liu, T. Yamamoto, D. Parker, M. Cinke, C. V. Nguyen, A. M. Arif and P. J. Stang, J. Am. Chem. Soc., 2004, 126, 10645.

142 P. H. Dinolfo and J. T. Hupp, Chem. Mater., 2001, 13, 3113.

143 S. S. Sun and A. J. Lees, J. Am. Chem. Soc., 2000, 122, 8956.

144 Y. Jung and S. Torquato, Phys. Rev. E: Stat., Nonlinear, Soft Matter Phys., 2005, 72, 056319.
145 D. Belitskus, G. A. Jeffrey, N. C. Stephenson and R. K. McMullan, Inorg. Chem., 1963, 2, 873.

146 A. Y. Manakov and J. Lipkowski, J. Inclusion Phenom. Mol. Recognit. Chem., 1997, 29, 41.

147 B. F. Abrahams, S. J. Egan and R. Robson, J. Am. Chem. Soc., 1999, $121,3535$.

148 H. Furukawa, J. Kim, N. W. Ockwig, M. O'Keeffe and O. M. Yaghi, J. Am. Chem. Soc., 2008, 130, 11650.

149 Z. Lu, C. B. Knobler, H. Furukawa, B. Wang, G. N. Liu and O. M. Yaghi, J. Am. Chem. Soc., 2009, 131, 12532.

150 A. C. Sudik, A. R. Millward, N. W. Ockwig, A. P. Cote, J. Kim and O. M. Yaghi, J. Am. Chem. Soc., 2005, 127, 7110.

151 M. Eddaoudi, J. Kim, J. B. Wachter, H. K. Chae, M. O'Keeffe and O. M. Yaghi, J. Am. Chem. Soc., 2001, 123, 4368.

152 C. Tedesco, I. Immediata, L. Gregoli, L. Vitagliano, A. Immirzi and P. Neri, CrystEngComm, 2005, 7, 449.

153 C. Tedesco, L. Erra, M. Brunelli, V. Cipolletti, C. Gaeta, A. N. Fitch, J. L. Atwood and P. Neri, Chem.-Eur. J., 2010, 16, 2371.

154 E. A. Lord and A. L. Mackay, Curr. Sci., 2003, 85, 346.

155 G. Horvath and K. Kawazoe, J. Chem. Eng. Jpn., 1983, 16, 470.

156 N. B. McKeown, S. Makhseed, K. J. Msayib, L.-L. Ooi, M. Helliwell and J. E. Warren, Angew. Chem., Int. Ed., 2005, 44, 7546.

157 S. Makhseed, F. Ibrahim, J. Samuel, M. Helliwell, J. E. Warren, C. G. Bezzu and N. B. McKeown, Chem.-Eur. J., 2008, 14, 4810.

158 Y. Jiao, F. H. Stillinger and S. Torquato, Phys. Rev. E: Stat., Nonlinear, Soft Matter Phys., 2009, 79, 041309.

159 N. B. McKeown and P. M. Budd, Macromolecules, 2010, 43, 5163.

160 F. C. Meldrum and R. Seshadri, Chem. Commun., 2000, 29.

161 D. Maspoch, N. Domingo, N. Roques, K. Wurst, J. Tejada, C. Rovira, D. Ruiz-Molina and J. Veciana, Chem.-Eur. J., 2007, 13, 8153 .

162 S. A. Dalrymple and G. K. H. Shimizu, J. Am. Chem. Soc., 2007, 129, 12114.

163 D. Maspoch, N. Domingo, D. Ruiz-Molina, K. Wurst, J. Tejada, C. Rovira and J. Veciana, J. Am. Chem. Soc., 2004, 126, 730.

164 D. Maspoch, N. Domingo, D. Ruiz-Molina, K. Wurst, G. Vaughan, J. Tejada, C. Rovira and J. Veciana, Angew. Chem., Int. Ed., 2004, 43, 1828.

165 C. J. Kepert, D. Hesek, P. D. Beer and M. J. Rosseinsky, Angew. Chem., Int. Ed., 1998, 37, 3158.

166 C. Tedesco, L. Erra, I. Immediata, C. Gaeta, M. Brunelli, M. Merlini, C. Meneghini, P. Pattison and P. Neri, Cryst. Growth Des., 2010, 10, 1527.

167 M. Simard, D. Su and J. D. Wuest, J. Am. Chem. Soc., 1991, 113, 4696.

168 J. D. Wuest, Chem. Commun., 2005, 5830.

169 N. Malek, T. Maris, M. Simard and J. D. Wuest, J. Am. Chem. Soc., 2005, 127, 5910.

170 J. H. Fournier, T. Maris and J. D. Wuest, J. Org. Chem., 2004, 69, 1762.

171 H. O. Finklea, M. A. Phillippi, E. Lompert and J. W. Grate, Anal. Chem., 1998, 70, 1268.

172 T. Kawamichi, T. Kodama, M. Kawano and M. Fujita, Angew. Chem., Int. Ed., 2008, 47, 8030.

173 J. N. Moorthy, P. Natarajan and P. Venugopalan, J. Org. Chem., 2009, 74, 8566 .

174 T. Sawaki, K. Endo, K. Kobayashi, O. Hayashida and Y. Aoyama, Bull. Chem. Soc. Jpn., 1997, 70, 3075.

175 K. Endo, T. Koike, T. Sawaki, O. Hayashida, H. Masuda and Y. Aoyama, J. Am. Chem. Soc., 1997, 119, 4117.

176 T. Hertzsch, C. Gervais, J. Hulliger, B. Jaeckel, S. Guentay, H. Bruchertseifer and A. Neels, Adv. Funct. Mater., 2006, 16, 268.

177 A. J. Cruz-Cabeza, G. M. Day and W. Jones, Chem.-Eur. J., 2009, 15, 13033.

178 C. P. Price, G. D. Glick and A. J. Matzger, Angew. Chem., Int. Ed., 2006, 45, 2062.

$179 \mathrm{http}: / /$ www.ccdc.cam.ac.uk/500000.php.

180 CSD codes: ABINOP, ADIYIV, BALNIM, EFALEC, FAKTIV, FOSTEM, GIPTOO, GOBSUL, IKANOX, KETYEO, KISYIV, NASQAA, PETREM, PICKAN, RERNEI, SULDUY, TIKFIC, TOZZIR, WAVJAE, XICRUW, XOPYEG and YUPTIM. 